present from his $\$ 2.00$ dues and, in addition, the two publications, the JourNaL, and the Year Book of the A. Ph. A., representing a retail value of $\$ 8.00$. Ten dollars for five is surely a striking offer, but it is only a fraction of the advantages offered by A. Ph. A. membership. Of even greater value than the material offer suggested above are the intangible but very real advantages that any pharmacist gains from being a part of the American Pharmaceutical Association.

What are the abstract advantages of $\mathrm{A}$. Ph. A. membership? To those of us who are active in its affairs the greatest pleasure comes from the privilege of carrying on the work, so wisely planned and conducted by the great men of American Pharmacy of twenty, or forty, or even sixty years ago. For sixty-six years the American Pharmaceutical Association has stood for the best in pharmacy and to-day it is still living up to its traditions. The influence of the A. $\mathrm{Ph}$. A. upon our calling in this country is immeasurable. Practically every State Association was founded upon its initiative. The Associations of Pharmacy colleges and of State boards were organized at meetings of the $\mathrm{A}$. Ph. $\mathrm{A}$. and still hold their meetings at the same place as and just prior to the A. Ph. A. convention. That potent influence in national legislation, the Drug Trade Conference, was the outcome of a discussion at an A. Ph. A. meeting and in its councils the A. Ph. A. wields much influence. Unsatisfactorily slow though it may be, whatever progress has been made in improving the status of pharmacists in the United States Army and Navy has been largely due to the efforts of the A. Ph. A. Committee created for that purpose in 1894 .

That standard of pharmaceutical practice, the National Formulary, is a child of the A. $\mathrm{Ph}$. A.; the $\mathrm{A}$. Ph. A. model pharmacy laws have been of great service in framing legislation in the several States of our Union; and now, always alert to the needs of the day, the interests of our return warrior pharmacists are being finely served by the Association's Advisory Committee for Soldier and Sailor Pharmacists.

This shows, sketchily and incompletely, what the American Pharmaceutical Association has done in the past and is doing in the present. How much more can it do in the future if federation with national organizations and with State Associations is brought to pass?

May not we of the A. Ph. A. Federation Committee ask your Association to give the proposition of combined dues your careful consideration at your 1919 meeting?

Bear in mind that the present status of the proposition is that we should take counsel together. The amendment to the A. Ph. A. by-law is at present merely proposed and it will not be acted upon until after the session of the house of delegates, at which the representatives of your Association will discuss the project with the delegates from other State Associations. So will you not at your approaching meeting study the proposition and then instruct the delegates you select to represent you at New York? And above all, select such delegates in order to beat the record of 1918 , when 32 State Associations chose delegates to the $\mathrm{A}$. Ph. A. meeting.

\title{
REPORT OF THE DELEGATES OF THE AMERICAN PHARMACEUTICAL ASSOCIATION TO THE AMERICAN ASSOCIATION OF PHARMACEUTICAL CHEMISTS.
}

\section{To the American Association of Pharmaceutical Chemists:}

Mr. E. G. Eberle and I have been appointed by the American Pharmaceutical Association to convey to you a message of fraternal regard and the wish that your meeting may prove successful. You will discuss many subjects of interest and importance, but probably none more so than the suggestion made by Dr. Charles Herty, editor of the Journal of Industrial and Engineering Chemistry, published by the American Chemical Society in regard to the establishment of a National Research Institute.

I was invited by Dr. Herty to attend the meeting of the New York branch of the American Chemical Society, where this subject was originally discussed. I was also invited by the editor of the Journal of the American Pharmaceutical Association to contribute a paper on the subject which appears in the April number under the title- "Proposed National Institute of Drug Research," and more recently I accepted an invitation to take part in a discussion of the plan by the Philadelphia branch of the American Chemical Society. In this discussion, Prof. H. V. Arny, of the New York College of Pharmacy, Prof. Charles H. LaWall, Chairman of the Revision Committee of the United States Pharmacopeia, and Dr. Herty himself, also 
took part. I present this subject to you for further discussion on account of its great importance, and, as the views presented by the members of the American Pharmaceutical Association who have discussed it in print appear to harmonize, I can probably do no better than repeat what I said during the recent discussion in Philadelphia to which I have just referred.

"It goes without saying that the future of any nation depends in large measure upon the degree to which the principles developed by original research are applied to the solution of economic and industrial problems. Two classes of research institutions and research workers are required, one for the development of principles, and the other for promoting their application.

"Two general types of research institutions exist, namely, those having as their object the promotion of pure science without regard to its practical application, and those having the practical application of the knowledge evolved by the researches as a primary object.

"Belonging to the type of research institutions for the promotion of pure science are the university research laboratories, the Government research laboratories, and the foundation research laboratories, the latter illustrated by the laboratories fostered by the Carnegie Institution, the Rockefeller Institute for Medical Research, the Geophysical Laboratories, the Magnetic Laboratory and the Mt. Wilson Observatory. These institutions are notably free from financial domination, and the results of their research work are public property. The industrial research institutions may be classified under general and specific types, those devoted to the promotion of certain classes of industry belonging to the former, and the research laboratories of the various manufacturing houses belonging to the latter.

"Research institutions may also be classified according to their motive, as altruistic or egotistic. Government research laboratories illustrate the altruistic class. Research institutions of this class are and should be supported by the Government, representing the people at large. The results of their work are public property and therefore their support by the taxation of the people is eminently right and proper.

"Research institutions having as their motive the promotion of any one class of industry belong to the egotistic type, and it would be exceedingly unfair to tax the entire people for their support. Just to the extent that the industry is antagonistic to some other industry in its operation, it partakes of the character of an army at war with an opposing army. Such institutions cannot therefore be properly established under governmental auspices.

"Then we have research institutions that may be of a mixed character, such, for example, as the research laboratories established by manufacturers engaged in the legitimate pharmacal and pharmaco-chemical industries. Notable examples of this class of research laboratories exist. The research work done by this class of laboratories is sometimes altruistic, being donated to the public, and at other times the results are appropriated for individual commercial use by the house, in which case the motive is egotistic.

"We have before us for consideration a plan for establishing a Research Institute for promoting the chemical industries. To what class of research institutions will this institute belong? My analysis of the data in relation to the plan leads me to classify the proposed institution as belonging to the egotistic type of research institutions, having as its motive the promotion of the use of medicinal chemicals.

"According to the plan as outlined in various communications on the subject, the object of the proposed Institute is to test new chemical substances upon animals in chemical and physio logical laboratories established for those purposes under the auspices of the proposed Institute, and then send them to the laboratories of the universities and to the public hospitals and dispensaries throughout the country, for clinical tests and reports.

"To carry out such a plan requires the coöperation of the medical profession and its educational institutions, including the medical societies and press and the teaching faculties of the medical schools and colleges. These educational institutions, according to this plan, are asked to coöperate with the chemical industries in promoting the use of new chemical substances as agents for the prevention and cure of disease.

"The question therefore arises: Are the results of this research to belong to the public or are they to be commercially controlled by the manufacturing houses engaged in the chemical industries? Is the manufacture and sale of these new chemical products to be monopolized by individual manufacturers by means of patents and alleged trademarks? If the results of researches are to belong to the public, so that all manufacturers may have equal right to make and sell the products, then the motive is altruistic, provided the products themselves are not limited to any 
one class of medicinal products, but embrace all kinds of products used for the prevention of disease and the treatment of the sick.

"I have just stated that if the plan includes the investigation of the materia medica from all possible points of view, the motive is altruistic. However, this statement must also be modified because the question of altruism is dependent upon the kind of advertising propaganda permitted, endorsed or tolerated by the Research Institute, if established according to the plan under discussion.

"As stated in many papers I have written on this subject of propaganda for introducing alleged new remedies during the past thirty years, tens of thousands of alleged new remedies have been introduced by advertising, and not more than one-tenth of one percent of them have proved of any permanent therapeutic value. This commercial introduction of alleged new remedies by advertising represents hundreds of thousands of useless experiments upon the sick by physicians in private and hospital practice, and many times that number of the self-medicating public. No one has profited by this so-called new remedy business except the manufacturers and the press-medical, pharmaceutical, secular and religious. In relation to the medical profession and the public, this state of affairs has done much to foster therapeutic drug nihilism. The claims made for the products in advertising have not been realized in the majority of instances, and as a result, both physicians and patients have been losing faith in drugs as remedial agents. While this nostrum business has enriched the manufacturers of these products, it has impoverished the medical and pharmaceutical professions, and seriously injured their prestige in public esteem. Among other disastrous results, it has been the means of throwing open the field of medical and pharmacal practice to exploitation by persons without education or training as physicians, pharmacists or chemists, to the injury of the public health.

"The only way that we can ever know the true value of drugs as prophylactic and remedial agents is by their free and unbiased discussion by competent observers, and the free publication of the knowledge thus evolved for the benefit of all concerned. In other words, the remedy is to be found in standardizing the materia medica and rendering drugs instruments of precision, which cannot be done under any system by which the manufacture and sale of the drugs themselves are commercially controlled by the manufacturing houses and a fictitious demand is created for them by misleading advertising, published in the advertising columns of a subsidized press.

"It is therefore apparent that what we need is a Research Institute devoted to the investigation of the newer materia medica, which shall include in its work all fields of materia medica research-a research institution that shall also deal with the problem of introducing newer materia medica products, so that the institute may not be utilized for promoting the commercial welfare of the nostrum business as against the interests of the public. If the plan of the American Chemical Society for a Research Institute can be so formulated and administered as to secure these objects, there can be no question whatever in regard to its importance and value to the American people."

In closing, I can no better express the views of the American Pharmaceutical Association than to quote the following from an editorial appearing in the May number of the JourNaL or THE A. PH. A., which statement is quoted from "A few comments on the proposed institute for drug research" appearing in the Chicago Chemical Bulletin for April:

"With all these commendable expressions, why do the promoters not rise to a plane of true altruism and propose that the Institute be a coöperative agency, actually unifying the best elements of chemistry, pharmacy and medicine? What good purpose or what logic is served in the insistence on keeping the Institute rigidly under the control of the American Chemical Society? $*_{*} *_{*} *$ The really big thing is to create a recognized research center not controlled by any one group or element; an institute whose policies are formulated by men of experience in the various affiliated branches of medico-chemical sciences and willingly seek the advice of all coöperative agencies. $* * * *$ Public health demands that evidence of supreme bigness out of which will rise a recognized national seat for critical drug research stripped of all professional or commercial pettishness and not dominated by any one group of scientists."

For the Delegates from the A. Ph. A.,

F. E. STEWART, Chairman. 